\title{
Structural and Functional Studies of Strigolactone Receptors of Striga hermonthica, its adaptation and evolution.
}

\author{
(Amir A. Arellano-Saab, Peter J. Stogios, Alexei Savchenko, Peter McCourt) \\ University of Toronto
}

Striga spp. is a genus of obligate root-parasitic plants, with the ability to deplete host roots from water, carbohydrates, and other essential nutrients. There are around $30-35$ species within the genus, and at least $80 \%$ of them are found in Africa. The most destructive species found in Africa is Striga hermonthica, with the ability to parasite major food crops, such as rice, millet, maize, and sorghum, producing high yield losses ranging from $30 \%$ to $100 \%$ of the crops (Berner, Kling, \& Singh, 1995).

Nowadays, the most common method to eliminate the parasitic plants is hand weeding, which is time-consuming, labour-intensive, and not very effective. It is thought that a complete understanding of the germination mechanism of Striga is necessary to develop targeted strategies to attack this weed. It has been proven that the germination of parasitic plants such as Striga and Orobanche is triggered by chemical factors called strigolactones (Toh et al., 2015).

Although the strigolactone receptor system has been studied, it is not completely characterized yet. It is known that the system is composed of 11 different receptors and each of them presents variable sensitivities to strigolactones. Several attempts to crystallize these receptors have been made, but only two structures have been reported so far, ShHTL3 (Xu et al., 2016) and ShHTL5 (Toh et al., 2015). It is essential to reveal the structural differences between the ShHTL receptors to understand its particular role in the strigolactone detection and establish the molecular basis for this detection. 